\title{
EDITORIAL
}

\section{EL ASEGURAMIENTO DE LA CALIDAD DE LA EDUCACIÓN SUPERIOR}

Asistimos a un escenario de cambio de época que afecta profundamente a la universidad. Este paradigma emergente destaca a la persona y la interdependencia de los sistemas. Esta nueva forma de entender el mundo está interesando a la sociedad, las organizaciones y la universidad. Dado que el paradigma mecanicista de la época moderna, no responde adecuadamente a las necesidades de hoy, el hombre comienza a buscar en su interior las respuestas a los problemas actuales y el camino para un nuevo desarrollo.

En este contexto la universidad, trata de mantener la estabilidad, mientras que las organizaciones empresariales avanzan con más agilidad en su respuesta y buscan soluciones creativas que respondan a las nuevas necesidades de las personas.

Así lo advierte Grajeda Gómez (1994) cuando declara que la preocupación por la calidad es uno de los signos de los tiempos, sobre todo la calidad referida al ser humano. Y la misión de la educación es precisamente esa: crear seres humanos de calidad

Por otro lado, desde el exterior se exigen cambios importantes a la universidad. Estas demandas de una sociedad basada en los conocimientos y de las nuevas tecnologías, han hecho del aprendizaje continuo un componente esencial de la dinámica social. Los ojos de la sociedad y de las organizaciones se vuelven hacia la universidad en demanda de ayuda y ésta debe dar la respuesta adecuada si quiere seguir cumpliendo con su función sustantiva en la formación de líderes y profesionales competentes y comprometidos con el bien común.

Así, la calidad emerge como un imperativo categórico para dar sentido al proceso de formación profesional y a la vez exige una definición objetiva, algunas de estas definiciones identifican a la calidad como excelencia, cumplimiento de los propósitos declarados, capacidad para transformar a los estudiantes durante su proceso formativo.

En ese sentido, se sintetizan los ejes conceptuales que permiten comprender la complejidad y el amplio espectro conceptual y práctico que subyace bajo la escueta categoría calidad, en especial cuando se trata de establecer criterios o parámetros de comprensión y reconocimiento en materia educativa. Podemos 
identificar criterios de la calidad como categoría histórica contextual, como inherente a la dignidad, como derecho y responsabilidad, como imperativo ético y político, lo que discurre en los componentes esenciales de la praxis educativa: a la intencionalidad mayor de la educación que no es otra que la plenitud humana y su relación fecunda con el entorno; a la alteridad de todo ser humano; al cuidado y desarrollo de la vida; al goce y felicidad como señal de sentido de vida. De ser así, acercarse a la noción compleja de calidad proyecto exige una permanente ponderación del sentido emancipador y productor de calidad de vida (Calidad en educación y derrotero, 2015).

En orden al aseguramiento de la calidad, una definición operacional de calidad, es la que facilita la aplicación de los criterios de evaluación basados en el logro de los propósitos declarados por las instituciones de educación superior, en la medida en que estos incorporen los elementos externos y los que provienen de su propia misión, principios y prioridades.

Así el aseguramiento de la calidad de la educación superior se entiende como «una expresión que describe un conjunto de mecanismos que apuntan al control, la garantía y la promoción de la calidad, cuyo propósito principal es entregar información a diferentes interesados para que tomen decisiones sobre el programa o la institución evaluada». Este procedimiento asume dos modalidades básicas: asegurar los niveles de calidad que existen y enfatizar los esfuerzos de mejora. Esto se fundamenta en una secuencia de actividades: un autoestudio o evaluación interna y externa, una certificación pública de la calidad y el monitoreo y seguimiento.

Por otro lado, la UNESCO, define a la evaluación de la educación superior como el «proceso de reunir, cuantificar y usar sistemáticamente información, con el objeto de juzgar la efectividad formativa y la pertinencia curricular de una institución de educación superior como un todo (evaluación institucional) o de sus programas educacionales (evaluación de programas). Implica la revisión de las actividades centrales de una institución de educación superior, incluyendo evidencia cualitativa y cuantitativa de las actividades educacionales y los productos de la investigación científica» (Vlascenanu, 2007).

Sin embargo, Annie Vinokur (2012) recuerda que la multiplicación de servicios de calidad en el sector de la educación es un fenómeno creciente, si bien es calificado por una institución oficial a nivel nacional, corresponde a los establecimientos educativos, generar y proporcionar a cada estudiante las herramientas para atender las necesidades que exige la sociedad para la inclusión en el medio profesional nacional. 
De allí que el aseguramiento de la calidad busque cumplir con el control de calidad, o cumplimiento de condiciones básicas o umbrales de calidad; la rendición de cuentas, o garantía de calidad; y el fomento o mejoramiento de la calidad.

Las Política de Aseguramiento de la Calidad definen las finalidades a partir de la Ley Universitaria: Fomento para mejorar el desempeño de las instituciones de educación superior, acreditación para la mejora continua y licenciamiento como garantía de condiciones básicas de calidad. A estos tres pilares se agrega un cuarto, referido a la provisión de información confiable y oportuna, disponible y accesible para todos los actores del sistema universitario.

Por otro lado, los actores principales de los procesos de aseguramiento de la calidad son los protagonistas de un proceso continuo de mejora de la calidad. Cada uno desde su especificidad ha de contribuir a este logro. Se puede destacar en primer lugar al Estado, quien a través de la legislación y el diseño y ejecución de políticas establece las prioridades y las condiciones para el ejercicio del aseguramiento de la calidad. Así mismo, un segundo actor relevante lo constituyen las instituciones de educación superior a quienes se les reconoce como principales responsables de la calidad.

Las agencias de aseguramiento de la calidad representan el tercer actor central quienes son responsables por la organización y administración de los procesos de licenciamiento o acreditación y tienen la responsabilidad de definir criterios y procedimientos y de establecer las condiciones que las instituciones deben cumplir.

Completa este compromiso los pares evaluadores que son académicos, gestores o profesionales destacados, que ponen al servicio de los procesos de aseguramiento de la calidad sus conocimientos y su experiencia.

El aseguramiento de la calidad avanza como exigencia de la formación. Se percibe que la calidad ha dejado de estar centrada en los productos o servicios para resaltar la satisfacción del cliente. Así toda la institución forma parte de la calidad y ha de esforzarse para que sean los beneficiarios los que determinen si la Universidad tiene o no calidad.

Pbro. Dr. Juan Roger Rodríguez Ruiz Editor en Jefe de la Revista In Crescendo 